\title{
Colorimetric Determination of Biphenyl Based on the Janovsky Reaction
}

\author{
Akio TANAKA and Yoshinori FuJIMOTo \\ Institute of Public Health in Saitama, Kami-ōkubo, Urawa, Japan \\ Received January 28, 1974
}

\begin{abstract}
The quantitatively nitrated product of biphenyl with potassium nitrate and sulfuic acid shows a characteristic red-purple color on reaction with isobutyl alcohol, acetone and alkali; this is the Janovsky reaction. The color reaction was sensitive, and the absorbance at $550 \mathrm{~nm}$ obeyed Beer's law at biphenyl concentrations between 2 and $40 \mu \mathrm{g}$ in $3.5 \mathrm{ml}$ of the reaction mixture. A procedure suitable for routine use is proposed.

The nitro-compound derived from biphenyl was identified as 2,2',4,4'-tetranitrobiphenyl by $R f$ on TLC, as well as by mixed melting point, IR and mass spectroscopy.
\end{abstract}

Biphenyl has been widely used as a fungistat to prevent rotting in citrus fruit during storage and transport. However, in order to avoid excess biphenyl residues in treated fruit, several countries have set tolerance limits.

Besides the ultraviolet absorption method, such as that proposed by A.O.A.C., ${ }^{11}$ the colorimetric method was also proposed by many investigators. $^{2 \sim 7)}$ Janovsky $^{8,9)}$ found that aromatic nitrocompounds treated with alkali, acetone and alcohol show a characteristic color. Recently Nakamura ${ }^{10)}$ has applied this reaction to a colorimetric determination for benzoic acid in food.

In this paper a colorimetric determination of biphenyl based on the Janovsky reaction was proposed and a nitro-compound derived from biphenyl was discussed.

\section{MATERIALS}

Analytical equipment. Absorbance measurements were made with a Hitachi spectrophotometer, Model EPS-032, with a rapid sampler attachment $(10 \mathrm{~mm}$ path length).

For the identification of nitro-compounds of biphenyl, thin-layer chromatography (TLC) was carried out on precoated silica gel plates. Silica gel $H_{254}$ was heated to $110^{\circ} \mathrm{C}$ for $2 \mathrm{hr}$ prior to use. The solvent system used was ethyl acetate-benzene $(1: 5)$, and the solvent front was $10 \mathrm{~cm}$ above the origin in all cases. Detection was done by viewing under short-wave UV light.
Melting points were determined with an electrothermal capillary melting point apparatus. Infrared spectra were recorded on a Jasco infrared spectrophotometer, Model IR-G. Mass spectra were obtained with a Hitachi RMU-6M mass spectrometer.

Reagents and solvents. Acetone, benzene, isobutyl alcohol, chloroform, ethyl acetate, $n$-hexane and D-limonene were all of analytical grade, obtained from Wako Pure Chemical Industries. Sulfuric acid, calcium carbonate and sodium hydroxide were of high purity, obtained from Kanto Chemical Co. The concentration of sodium hydroxide solution was adjusted to $0.025 \mathrm{~N}(\mathrm{~F}=0.9$ to 1.1$)$ for general use. Silica gel $\mathrm{HF}_{254}$ was obtained from Mallinckrodt Chemical Works.

Biphenyl and 2,2',4,4'-tetranitrobiphenyl were of high purity, obtained from Wako Pure Chemical Industries. Standard solutions of biphenyl were prepared by dissolving $100 \mathrm{mg}$ biphenyl in $100 \mathrm{ml} n$-hexane. The standards thus prepared were stable at ambient temperature over a period of several weeks and were diluted to the desired concentration with $n$-hexane for use.

\section{RESULTS AND DISCUSSION}

1. Proposed determination procedure for $b i$ phenyl

Evaporation of solvent. A suitably diluted biphenyl standard solution or purified extract was placed in a test tube $(3 \mathrm{~cm}$ i.d. $\times 16 \mathrm{~cm}$ length) with a tapered capillary tube ( $2 \mathrm{~mm}$ i.d. $\times c a .17 \mathrm{~cm}$ length) sealed to the upper end and fitted to a filtration jar with a rubber 
stopper. The tip of the tapered capillary was set ca. $0.5 \mathrm{~mm}$ from the bottom of the test tube. Dried air passed through sulfuric acid placed in a filtration jar was permitted to flow through the test tube to evaporate the $n$ hexane. The $n$-hexane was carefully evaporated in dry air at room temperature to avoid vaporization of biphenyl. After the removal of the $n$-hexane, the stopper with the tapered capillary was removed. As the biphenyl residue in the test tube tended to sublime, nitration was carried out within 2 min after the evaporation of the solvent.

Nitration of biphenyl. The biphenyl residue in the test tube was dissolved in $0.5 \mathrm{ml}$ of sulfuric acid and 0.1 to $0.2 \mathrm{~g}$ of potassium nitrate. With occasional shaking, the test tube was placed in a water bath and kept in boiling water for $45 \mathrm{~min}$. After being cooled to room temperature, the sample was transfused with 20 to $30 \mathrm{ml}$ of distilled water into a $100-\mathrm{ml}$ separating funnel to which $20 \mathrm{ml}$ of isobutyl alcohol was then added. The mixture was well shaken for 3 to $5 \mathrm{~min}$ and the layers were separated. The isobutyl alcohol extracts were washed with 20 $\mathrm{ml}$ of $1 \%$ sulfuric acid and transfered to a $50-\mathrm{ml}$ centrifuge tube with a stopper.

The extracts were neutralised with $0.1 \mathrm{~g}$ of calcium carbonate and then centrifuged until separation was complete. The neutralized upper isobutyl alcohol layer was used for the colorimetric determination.

Colorimetric determination. Upon addition of $2 \mathrm{ml}$ of acetone and $1 \mathrm{ml}$ of $0.025 \mathrm{~N}$ sodium hydroxide to $0.5 \mathrm{ml}$ of the isobutyl alcohol extract, the mixture quickly developed a redpurple color. The absorption spectrum is shown in Fig. 1. Since the maximum absorption was found at $550 \mathrm{~nm}$, quantitative measurements were carried out at $550 \mathrm{~nm}, 10,15$ and $20 \mathrm{~min}$ after the color development. The maximum reading was adopted to determine the biphenyl content.

Calibration graph. A series of working standard biphenyl solutions were prepared by

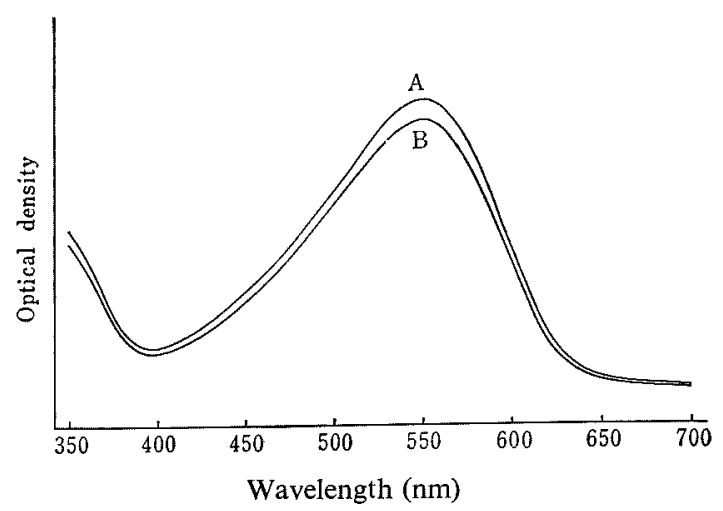

FIG. 1. Absorption Spectra of the Compounds Produced by Color Reaction.

A, nitro-compound of biphenyl; B, 2,2',4,4'-tetranitrobiphenyl.

diluting the stock solution with $n$-hexane. Aliquots were taken in test tubes to give amounts of $0.1,0.3,0.5,0.7,1.0$ and $1.5 \mathrm{mg}$ of biphenyl. According to the procedure described above, $20 \mathrm{ml}$ of isobutyl alcohol extract was obtained in each case. An aliquot of 0.5 $\mathrm{ml}$ was taken for color formation. When $1 \mathrm{ml}$ of the standard stock solution was taken, therefore, $3.5 \mathrm{ml}$ of reaction mixture, which consisted of $0.5 \mathrm{ml}$ of the extract, $1 \mathrm{ml}$ of alkali and $2 \mathrm{ml}$ of acetone, contained $25 \mu \mathrm{g}$ of biphenyl. The graph obtained gave a straight line, as shown in Fig. 2. Beer's law was obeyed at concentrations between 2 and $40 \mu \mathrm{g}$ of biphenyl

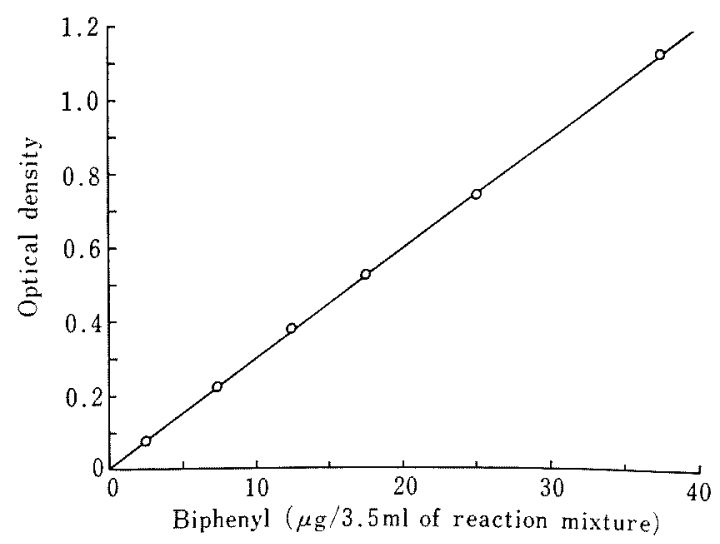

FIG. 2. Standard Curve for Biphenyl Determination. Wavelength, $550 \mathrm{~nm}$; cell thickness, $10 \mathrm{~mm}$. 
in $3.5 \mathrm{ml}$ of the reaction mixture.

\section{Comments on the proposed procedure}

Before the proposal of the above procedure for determining biphenyl, the following points were examined.

Influence of evaporation of the solvent on the biphenyl recovery. Prior to the nitration of biphenyl it was necessary to evaporate off the $n$-hexane. As biphenyl is volatile, possible loss during or after evaporation of the solvent should not be overlooked. 0.5 or $15 \mathrm{ml}$ of $n$-hexane which contained 0.5 or $1.0 \mathrm{mg}$ of biphenyl was evaporated by dry air flow at room temperature. The loss of biphenyl during the evaporation was scarcely observable. One of experiments, where $15 \mathrm{ml}$ of $n$-hexane was evaporated for $c a .40 \mathrm{~min}$, is shown in Table I. However, after the $n$-hexane had been

TABLE I. INFLUENCE OF THE EVAPORATION OF THE SOLVENT ON BIPHENYL ReCOVERY

The amount of $n$-hexane was $15 \mathrm{ml}$.

\begin{tabular}{cccc}
\hline Sample No. & $\begin{array}{c}\text { Biphenyl } \\
\text { added (m) }\end{array}$ & $\begin{array}{c}\text { Biphenyl } \\
\text { remaining } \\
(\mathrm{mg})\end{array}$ & $\begin{array}{c}\text { Recovery } \\
(\%)\end{array}$ \\
\hline 1 & 0.50 & 0.495 & 99 \\
2 & 0.50 & 0.490 & 98 \\
3 & 0.50 & 0.490 & 98 \\
4 & 0.50 & 0.485 & 97 \\
5 & 1.00 & 0.990 & 99 \\
6 & 1.00 & 0.990 & 99 \\
7 & 1.00 & 0.990 & 99 \\
8 & 1.00 & 0.970 & 97 \\
\hline
\end{tabular}

removed and biphenyl remained as the residue, the decrease of biphenyl was significant, as shown in Table II. Therefore, the sample should be nitrated within 2 min after the removal of the $n$-hexane.

Conditions for nitration. For the nitration of biphenyl, $0.05,0.1,0.2,0.3$ or $0.4 \mathrm{~g}$ of potassium nitrate was added to $1 \mathrm{mg}$ of biphenyl with $0.5 \mathrm{ml}$ of sulfuric acid. The nitration was almost complete in $30 \mathrm{~min}$ on boiling water and no difference was found with any of the above amounts of potassium nitrate. After the nitration, the resulting nitro-compound was stable for at least 3 days at room temperature as isobutyl alcohol solution.

Color development of the nitro-compound. Color development depended significantly upon the mixing rate of reagents, alkali concentration and temperature. Figures 3 and 4 show the time curves of color formation under various conditions. The volume of isobutyl alcohol was unchanged and the relative amounts of acetone and alkali were varied from 2 to 4 times. The absorbances at various combinations are illustrated in Fig. 3. Where the proportions of isobutyl alcohol, acetone and alkali were $1: 2: 4$, the absorbance was most intense and the time required to reach the maximum was short. As illustrated in Fig. 4, when 0.05 $\mathrm{N}$ sodium hydroxide was used with this combination, color development was rapid, but fading was significant. With $0.075 \mathrm{~N}$ sodium hydroxide, similar phenomena were observed. However, with $0.025 \mathrm{~N}$ sodium hydroxide, color development was gradual and the color was stable for $30 \mathrm{~min}$.

The effect of temperature on color development was marked. Although the development and fading of color were accelerated at higher temperature, the value of the maximum absorbance was constant, at least in the range

Table II. Decrease of Biphenyl Residue after Evaporation of the Solvent Biphenyl content before evaporation was $1.00 \mathrm{mg}$. The volume of $n$-hexane was $1 \mathrm{ml}$ for $\mathrm{I}$ and $15 \mathrm{ml}$ for II, and the tests were carried out at room temperature.

\begin{tabular}{lccccccccc}
\hline $\begin{array}{c}\text { Time after completion } \\
\text { of evaporation (min) }\end{array}$ & 0 & 1 & 2 & 3 & 5 & 10 & 15 \\
\hline $\begin{array}{c}\text { Biphenyl recovered } \\
(\mathrm{mg})\end{array}$ & $\mathrm{I}$ & 0.99 & 0.99 & 0.98 & 0.91 & 0.88 & 0.82 & 0.785 \\
\cline { 2 - 9 } & II & 0.99 & 0.99 & 0.98 & 0.90 & 0.88 & 0.82 & 0.79 \\
\hline
\end{tabular}




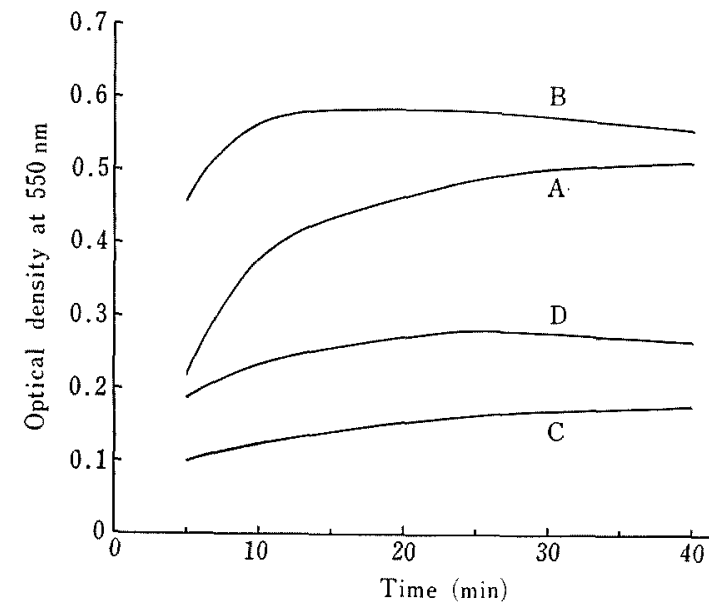

FIG. 3. Time Courses of Color Development at Various Mixing Rates of Reagents.

\begin{tabular}{ccccc}
\hline \multicolumn{5}{c}{ Amount of reagent (ml) } \\
\hline & $\begin{array}{c}\text { Isobutyl } \\
\text { alcohol } \\
\text { extract }^{\text {al }}\end{array}$ & $\begin{array}{c}0.025 \mathrm{~N} \\
\mathrm{NaOH}\end{array}$ & Acetone & Total \\
\hline A & 0.5 & 1.0 & 1.0 & 2.5 \\
B & 0.5 & 1.0 & 2.0 & 3.5 \\
C & 0.5 & 2.0 & 1.0 & 3.5 \\
D & 0.5 & 2.0 & 2.0 & 4.5 \\
\hline
\end{tabular}

a) The amount of biphenyl in the solvent was ca. $20 \mathrm{\mu g}$.

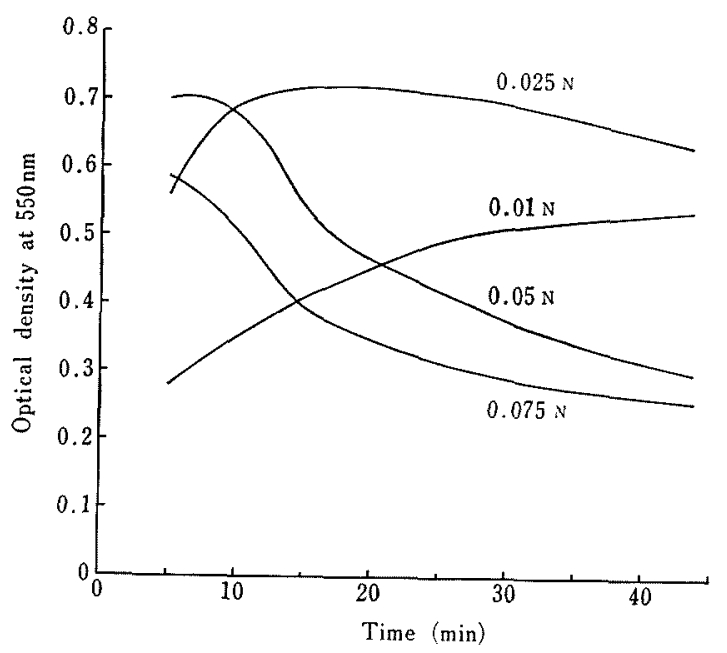

Fig. 4. Effect of $\mathrm{NaOH}$ Concentration on Color Development.

The amounts of isobutyl alcohol extract, $0.025 \mathrm{~N}$ $\mathrm{NaOH}$ and acetone in the reaction mixture were 0.5 , 1.0 and $2.0 \mathrm{ml}$, respectively, and that of biphenyl in the solution was $c a .25 \mu \mathrm{g}$. of room temperature. In order to avoid complexity in keeping the temperature constant, for routine work, the absorbance was observed 5 , 10 and $15 \mathrm{~min}$ after color development. The highest value was adopted.

\section{Effect of limonene}

The effect of an essential oil on the quantitative analysis of biphenyl, used for preserving citrus fruits, should not be overlooked. Since citrus fruits obtained in the market are generally treated with biphenyl, it is not possible to obtain a biphenyl free from essential oil by distillation. Therefore, the influence of limonene, which is the most common essential oil of citrus fruits, was examined. Mixtures of biphenyl and limonene were nitrated and quantitatively analyzed, and the results are shown in Table III.

Table III. Influence of Limonene on Color DEVELOPMENT

\begin{tabular}{ccccc}
\hline $\begin{array}{c}\text { Sample } \\
\text { No. }\end{array}$ & $\begin{array}{c}\text { Biphenyl } \\
(\mathrm{mg})\end{array}$ & $\begin{array}{c}\text { Limonene } \\
(\mathrm{mg})\end{array}$ & $\begin{array}{c}\text { Biphenyl } \\
\text { found(mg) }\end{array}$ & $\begin{array}{c}\text { Recovery } \\
(\%)\end{array}$ \\
\hline 1 & 0.50 & 5 & 0.50 & 100 \\
2 & 0.50 & 10 & 0.50 & 100 \\
3 & 0.50 & 20 & 0.51 & 102 \\
4 & 0.50 & 30 & 0.55 & 110 \\
5 & 0.50 & 40 & 0.35 & 70 \\
6 & 1.00 & 5 & 1.00 & 100 \\
7 & 1.00 & 10 & 0.98 & 98 \\
8 & 1.00 & 20 & 1.01 & 101 \\
9 & 1.00 & 30 & 1.01 & 101 \\
10 & 1.00 & 40 & 0.53 & 53 \\
\hline
\end{tabular}

Color development for 0.5 or $1.0 \mathrm{mg}$ of biphenyl was not affected by limonene up to $30 \mathrm{mg}$. However, on addition of limonene over $40 \mathrm{mg}$, color development was inhibited. The results suggest that it is preferable to remove essential oils prior to the nitration of biphenyl mixtures extracted from citrus fruits.

\section{Identification of the nitro-compound of biphenyl}

On the basis of preliminary experiments, the isobutyl alcohol extract obtained after the nitration of biphenyl was assumed to be $2,2^{\prime}$, $4,4^{\prime}$-tetranitrobiphenyl. Several examinations were carried out to compare the nitration pro- 
duct with authentic $2,2^{\prime}, 4,4^{\prime}$-tetranitrobiphenyl.

Thin-layer chromatography. $5 \mu \mathrm{l}$ aliquots of isobutyl alcohol solutions containing $25 \mu \mathrm{g}$ of biphenyl, the nitration product and authentic $2,2^{\prime}, 4,4^{\prime}$-tetranitrobiphenyl were applied to TLC plates of silica gel $\mathrm{HF}_{254}$. The solvent system was that cited previously. The $R f$ values were 0.95 for biphenyl and 0.82 for both the product and $2,2^{\prime}, 4,4^{\prime}$-tetranitrobiphenyl.

Melting point. Crystals of the product were obtained from the spots on the TLC plates and recrystallized three times from ethylacetate. They were yellow needles with a melting point of 163 to $164^{\circ} \mathrm{C}$. The mixed melting point of the product and authentic $2,2^{\prime}, 4,4^{\prime}$-tetranitrobiphenyl was not depressed.

Infrared and mass spectra. The samples, which were collected from the spots on the TLC and dissolved in chloroform, were used for infrared analysis or were run into a mass spectrometer directly.

As shown in Fig. 5, the infrared spectra of the product and an authentic sample of $2,2^{\prime} 4,4^{\prime}$ tetranitrobiphenyl were identical.

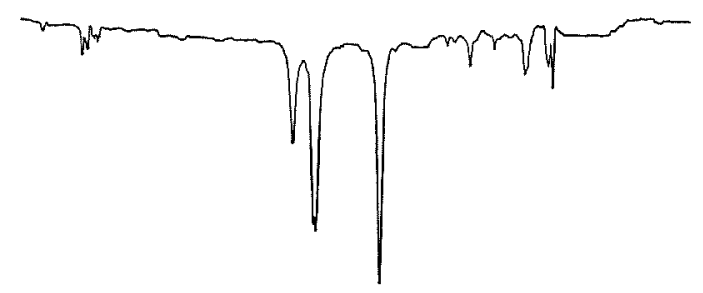

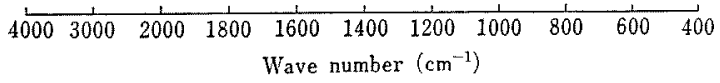

FIG. 5. Infrared Spectrum of the Nitro-compound of Biphenyl.

The spectrum of authentic $2,2^{\prime}, 4,4^{\prime}$-tetranitrobiphenyl was identical.

The mass spectrum of the product, which is shown in Fig. 6, showed a parent peak at $m / e 334$ and peaks corresponding to the loss

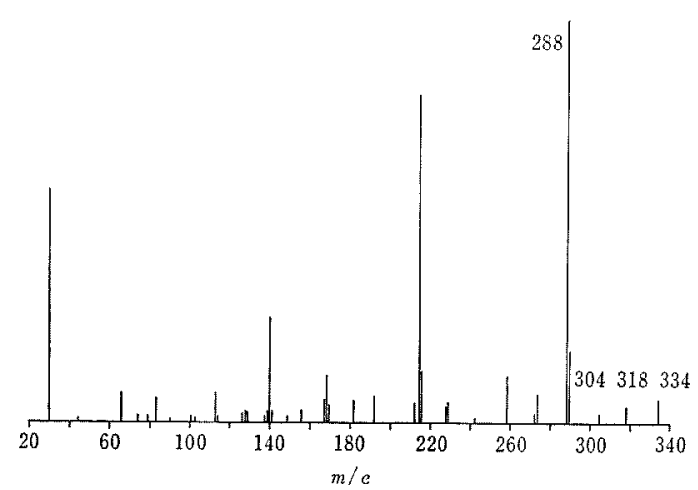

FIG. 6. Mass Spectrum of the Nitro-compound of Biphenyl.

Sample temperature: $110^{\circ} \mathrm{C}$.

parent ion. The spectrum was identical with that of authentic $2,2^{\prime}, 4,4^{\prime}$-tetranitrobiphenyl.

Color reaction. Color developments of the product and of $2,2^{\prime}, 4,4^{\prime}$-tetranitrobiphenyl treated with isobutyl alcohol, acetone and alkali were identical and gave the same spectra, as shown by A and B in Fig. 1.

From this series of examinations, therefore, it was concluded that the nitro-compound of biphenyl was $2,2^{\prime}, 4,4^{\prime}$-tetranitrobiphenyl.

\section{REFERENCES}

1) Official Methods of Analysis of the A.O.A.C., 11th ed., p. 490 (1970).

2) R. G. Tomkins and F. A. Ischerwood, Analyst, 70, 330 (1945).

3) R. B. Bruce and J. W. Howard, Anal. Chem., 28, 1973 (1956).

4) F. Haecke and H. Cats, Chem. Weekbl., 53, 609 (1957).

5) E. Benk and A. Krehl, Fruchtsaftindustrie, 2, 86 (1957).

6) H. Böhme and G. Hofmann, Z. Lebensmitt. Untersuch., 114, 96 (1961).

7) A. Rajzman, Analyst, 85, 116 (1960).

8) J. V. Janovsky, Ber., 19, 2158 (1886).

9) J. V. Janovsky, ibid., 24, 971 (1891).

10) Y. Nakamura, J. Food Hyg. Soc. Japan, 10, 272 (1969). of $\mathrm{O}(318), \mathrm{NO}(304)$ and $\mathrm{NO}_{2}(288)$ from the 